\title{
Does patellar denervation prevent anterior knee pain and improve patient-reported outcomes in patients undergoing non-resurfaced total knee arthroplasty? an updated meta-analysis of randomized controlled trials.
}

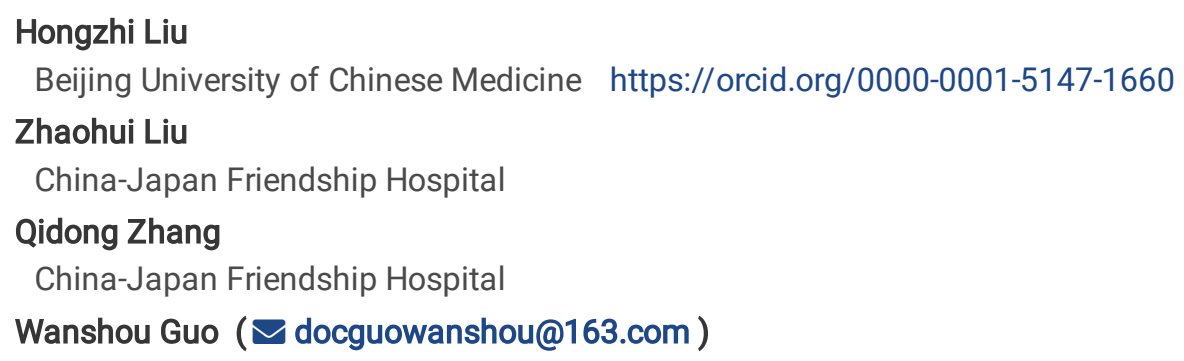

Research article

Keywords: Patellar denervation, Anterior knee pain, Total knee arthroplasty, Meta-analysis

Posted Date: May 11th, 2020

DOI: https://doi.org/10.21203/rs.3.rs-26676/v1

License: () (7) This work is licensed under a Creative Commons Attribution 4.0 International License. Read Full License 


\section{Abstract}

Background Anterior knee pain (AKP) is the most common complication of total knee arthroplasty (TKA). It is unclear which procedure of addressing AKP is preferable. Some data suggest patellar denervation (PD) provides effective AKP prevention. The purpose was to assess the effectiveness and safety of PD in primary TKA.

Methods A meta-analysis was performed of randomized clinical trials (RCTs) from inception to March 26, 2020, using PubMed, Embase, Web of Science and Cochrane Library. Study-specific RR and MD were aggregated using random or fixed effects models. The outcomes were incidences of AKP, PS (patellar scores), VAS (visual analogue scale), ROM (range of motion), KSS knee (American Knee Society knee scores), KSS function (American Knee Society function scores), incidence of complications and revisions.

Results Ten RCTs involving 1196 knees were included. The meta-analysis showed no significant in PD group on the incidence of AKP $(R R=0.64 ; 95 \% \mathrm{Cl} 0.37,1.11 ; p=0.11)$ with moderate heterogeneity $\left(P<0.01, I^{2}=84 \%\right)$. Our results indicated $P D$ had a significantly better VAS (MD $=-0.25 ; 95 \% \mathrm{Cl}-0.41,-0.09 ; \mathrm{p}<0.01)$, ROM (MD = 7.68; $95 \% \mathrm{Cl} 0.34,15.20 ; \mathrm{p}=0.04)$ and $\mathrm{PS}(\mathrm{MD}=0.91 ; 95 \% \mathrm{Cl} 0.36$, $1.46 ; p<0.01)$. However, there was no significant difference no matter in KSS knee, KSS function, complications or revisions.

Conclusions This meta-analysis showed that no difference in AKP between PD and NPD in patients undergoing non-resurfaced TKA. PD could improve clinical outcome in VAS, post-operative ROM and PS.

\section{Background}

Anterior knee pain (AKP) is the most common complication of total knee arthroplasty (TKA) with patellar resurfacing and nonresurfacing technique [1]. With a prevalence of 4-49\% [2, 3, 4], AKP could compromise patient satisfaction and range of motion. Determinants of anterior knee pain are multifactorial, and risk factors predicting whether this complication will be present remain unclear.

Dye [5] found that the peripatellar soft tissue is rich in substance $P$ nerve fibers as a possible source of anterior knee pain. There is a network of superficial sensory nerves that innervates the patella including the anterior femoral cutaneous nerve, lateral and medial femoral cutaneous nerves, and lateral and medial retinacular nerves [6]. Theoretically, denervation of the anterior knee region and relief of patellofemoral pain might be achieved by cauterizing these nerve fibers with electrocautery.

Previous studies have compared the outcomes of denervation and no denervation patellae in patients following primary TKA [7]. Although some studies have revealed that patellar denervation (PD) may decrease the incidence of anterior knee pain [2, 8, 9], others have indicated that patellar denervation had no substantial effect during follow-up $[3,10,11,12,13]$.

Several meta-analyses have been performed to evaluate the effectiveness with versus without denervation. Nevertheless, controversy still exists, which is partly related to provided evidence. A few deficiencies could be observed in previous studies: First, inclusion of updated RCTs published in recent years might alter the results of previous meta-analyses; Second, involved outcomes were inadequate; Third, few studies were included, and the quality was not reliable.

Therefore, it is necessary to make a more comprehensive and latest meta-analysis composed of all RCTs to evaluate the effectiveness of PD in primary TKAs. We hypothesized that PD has a superior effect on the incidence of AKP and the clinical outcome in primary TKAs compared with no patellar denervation (NPD).

\section{Methods}

\section{Search Strategy and Selection Criteria}

We performed a systematic review and meta-analysis of RCTs using a predefined protocol as per the Preferred Reporting Items for Systematic Reviews and Meta-analyses (PRISMA) recommendations [14]. Two of us (H.L. and Q.Z.) independently searched PubMed, Embase, Web of Science, and Cochrane Library databases for relevant articles (from inception to March 26, 2020). The computerbased searches combined terms and combinations of keywords related to the population (eg, knee replacement and knee arthroplasty), intervention (eg, denervation, patella, and electrocautery), and outcome (eg, RCT, AKP and complication) in humans, with no language restrictions. The search strategy and specific terms used are listed in the Supplement. Two of us (H.L. and Q.Z.) independently screened titles and abstracts of all initially identified studies according to the selection criteria. Full-text articles of 
studies meeting the selection criteria were retrieved. Reference lists of selected studies and relevant review articles were manually searched for relevant articles.

We included RCTs assessing the clinical effectiveness of patellar denervation in patients undergoing TKA without resurfacing. Patients had to be randomized to denervation or no denervation for inclusion. We excluded all other study types (quasi-randomized, nonrandomized and observational studies). The outcomes were postoperative pain, function and complications. No limits were placed on study follow-up duration.

\section{Data Extraction and Quality Assessment}

The data extraction was conducted by 2 of us (H.L. and Q.Z.) independently. In cases of inconsistency, consensus was reached by a third author (Z.L.). A standardized predesigned data extraction form was used to obtain the relevant data from each study, including author, publication year, baseline demographic characteristics, numbers enrolled and randomized, allocation concealment, blinding, interventions, outcomes of interest, and follow-up duration. In cases of multiple publications involving the same study, the most up-todate or comprehensive information was extracted.

Potential sources of bias in RCTs were assessed using the Cochrane Collaboration's risk of bias tool [15], which assesses the following 7 possible sources of bias: random sequence generation, allocation concealment, blinding of participants and personnel, blinding of outcome assessment, incomplete outcome data, selective reporting, and other bias. For each individual domain, studies were classified as having low, unclear, or high risk of bias.

\section{Statistical Analysis}

Summary measures are presented as relative risks (RRs) with 95\% Cls. We used reported RRs, or we calculated risk estimates for studies that reported raw counts. Heterogeneity was assessed using the Cochrane $\chi 2$ statistic and the $I^{2}$ statistic. Random-effects models, which take into account heterogeneity within and between studies, were used to combine RRs. Parallel analyses used fixedeffects models. The decision to use random-effects or fixed-effects models was based on $\mathrm{I}^{2}$ quantification of heterogeneity, as well as variability in the clinical and methodological aspects of the studies, number of studies available for pooling, and study sample sizes $[16,17]$. The $Q$ and chi-square tests were used to estimate statistical heterogeneity with the values of $P$ and $I^{2}$. If $I^{2}$ was $>50 \%$ and $P$ was $<0.1$, a random effects model was utilized. Otherwise, a fixed effects model was applied. Potential for publication bias was assessed through Begg's test. Where possible, sensitivity analysis was planned to examine various aspects of trial and review methodology, including worst and best scenario analyses for missing data and the effects of trials at high risk of bias. Subgroup analyses was planned to perform by study-level characteristics, such as year of publication, follow-up duration, and type of implant, if possible. A statistical software program (R software version 3.5.1 R Foundation for Statistical Computing, Vienna, Austria) was used for all analyses. The level of statistical significance was set as $\mathrm{P}<.05$, with $95 \%$ Cls also used. All statistical tests performed were 2 sided.

\section{Results}

\section{Study Identification}

A total of 115 potentially relevant citations were initially identified with our search strategy; 3 additional reports were found during the manual search of references. Sixty duplicate studies were excluded with Endnote Software (Version X9, Thompson Reuters, CA, USA). Additional 45 studies were removed after screening the title and abstract. Then 13 articles remained for full-text assessment. Three were subsequently excluded. Ten RCTs $[2,3,11,12,13,18,19,20,21,22]$ met the meta-analysis inclusion criteria. The PRISMA flow diagram is presented in Figure 1.

\section{Study Characteristics}

The 10 RCTs $[2,3,11,12,13,18,19,20,21,22]$ included 1011 knees (508 in PD and 503 in NPD). 1 study [20] was from North Africa, and 4 studies $[3,11,12,18]$ were from Europe, 5 studies $[2,13,19,20,21]$ were from Asia. The detailed characteristics of the studies are listed in Table 1.

Risk of Bias 
Using the Cochrane Collaboration's risk of bias tool [15], a total of 3 trials $[13,18,22]$ had a high risk of bias, with each study having between 3 and 5 of the 7 possible sources of bias. Bias was most common in blinding of participants and personnel followed by blinding of outcome assessment and allocation concealment. Seven studies $[2,3,11,12,19,20,21]$ had a low risk of bias in all domains (Figure 2 and 3 ).

\section{Results of meta-analysis}

\section{Postoperative pain}

\subsection{AKP}

Five studies $[11,12,13,18,22]$ including 327 knees in PD and 323 knees in NPD reported the incidences of post-operative AKP. The pooled risk of AKP after THA in patients receiving PD was not statistically significantly different from the risk in patients receiving NPD, though PD was associated with lower incidence of AKP compared with NPD (RR $=0.64 ; 95 \% \mathrm{Cl} 0.37,1.11 ; p=0.11)$. There was evidence of heterogeneity between the included studies $\left(P<0.01, \mathrm{I}^{2}=84 \%\right)$ and a random effects model was applied (Figure 4$)$.

\subsection{VAS (visual analogue scale)}

Three studies $[2,11,21]$ composed of 148 knees in PD and 147 knees in NPD reported the VAS. The result showed significant difference between PD and NPD in VAS scores (MD $=-0.25 ; 95 \% \mathrm{Cl}-0.41,-0.09 ; \mathrm{p}<0.01)$ with no heterogeneity $\left(P=0.26, \mathrm{I}^{2}=25 \%\right)$, so a fixed effects model was used (Figure 5).

\section{Postoperative function}

\subsection{ROM (range of motion)}

Three trials $[2,11,18]$ including 190 knees in PD and 190 knees in NPD reported the details of post-operative ROM. The pooled results showed that $P D$ was related to a greater increase in $R O M(M D=7.68 ; 95 \% \mathrm{Cl}, 0.34,15.02 ; P=0.04)$ with high heterogeneity $(P<0.01$, $\mathrm{I}^{2}=95 \%$ ) and a random effects model was applied (Figure 6).

\subsection{PS (patellar scores)}

Four studies $[2,11,19,20]$ consisting of 194 knees in PD and 194 knees in NPD reported the results of post-operative PS. The results showed significant difference between PD and NPD in PS (MD = 0.91; $95 \% \mathrm{Cl} 0.36,1.46 ; p<0.01)$ without heterogeneity $\left(P=0.12, I^{2}=\right.$ $49 \%$ ), and a fixed effects model was used (Figure 7).

\subsection{3-month post-operative PS}

Three trials $[11,19,20]$ involving 159 knees in PD and 159 knees in NPD reported the results of 3-month post-operative PS. The result through a random effects model showed no significant difference between PD and NPD in 3-month post-operative PS (MD $=1.5 ; 95 \%$ $\mathrm{Cl}-0.76,3.75 ; \mathrm{p}=0.19)$ with high heterogeneity $\left(\mathrm{P}<0.01, \mathrm{I}^{2}=89 \%\right)$, though $\mathrm{PD}$ was related to a greater increase (Figure 8 ).

\subsection{KSS knee (American Knee Society knee scores)}

Four trials $[2,11,19,20]$ involving 194 knees in PD and 194 knees in NPD reported the details of post-operative KSS knee. There was no significant difference between PD and NPD in KSS knee (MD = 0.90; $95 \% \mathrm{Cl}-0.61,2.40 ; P=0.24)$ with no heterogeneity $\left(P=0.23, I^{2}\right.$ $=30 \%$ ), and a fixed effects model was used (Figure 9).

\subsection{KSS function (American Knee Society function scores)}

Three trials $[2,11,20]$ consisting of 144 knees in PD and 144 knees in NPD reported the details of post-operative KSS function. The pooled results through a random effects model showed no significant difference between PD and NPD in American Knee Society function scores $(\mathrm{MD}=1.99 ; 95 \% \mathrm{Cl}-2.13,6.10 ; \mathrm{P}=0.34)$ with high heterogeneity $\left(\mathrm{P}=0.02, \mathrm{I}^{2}=76 \%\right)$ (Figure 10).

\section{Complications}

\subsection{Total incidence of complications}


Eight studies $[2,3,11,12,13,18,19,22]$ involving 503 knees in PD and 502 knees reported the complications and showed no significant difference between PD and NPD (RR 1.06; $95 \% \mathrm{Cl} 0.53,2.14 ; p=0.87)$ with no heterogeneity $\left(p=0.47,1^{2}=0.00 \%\right)$, and a fixed effects model was used (Figure 11).

\subsection{Total incidence of revisions or re-operation}

Eight studies $[2,3,11,12,13,18,19,22]$ involving 503 knees in PD and 502 knees reported the complications and revealed no significant difference between PD and NPD (RR $0.48 ; 95 \% \mathrm{Cl} 0.19,1.17 ; \mathrm{p}=0.10)$ with no heterogeneity, and a fixed effects model was used $\left(p=0.65, l^{2}=0.00 \%\right)$ (Figure 12).

\section{Publication Bias}

For comparisons involving studies, Begg's tests for studies of AKP $(p=0.32)$, VAS $(p=0.60), \operatorname{ROM}(p=0.60), P S(p=0.17), 3$-month post-operative PS $(p=0.12)$, KSS knee $(p=0.99)$, KSS function $(p=0.60)$, complication $(p=0.99)$ and revision $(p=0.12)$ were performed to quantitatively evaluate, demonstrating no statistically significant evidence of publication bias $(p>0.05)$.

\section{Sensitivity analysis}

Because of insufficient data, we performed sensitivity analyses only to examine the primary outcome of interest (AKP). The results in our sensitivity analysis, consistent with those in non-sensitivity analysis, indicated that our data were stable and credible.

\section{Subgroup analysis}

Because of limited data, subgroup analysis also only assessed the primary outcome of interest (AKP). There were evidences of effect modification by the clinically relevant study-level characteristics explored possibly in location or year of publication, and follow-up duration. Subgroup analyses by study-level characteristics in depth of electrocautery did not show any evidence of effect modification (Figure 13).

\section{Discussion}

This meta-analysis of RCTs demonstrated that there was no statistically significant difference in the risk of AKP when comparing PD with NPD undergoing TKA without patellar resurfacing. PD had statistically significantly pooled decrease in VAS and increase in postoperative PS and ROM.

Our findings are similar with a prospective, quasi-randomized study [10], which have reported that patellar denervation results in no statistically significant difference in incidence of anterior knee pain, though our study showed PD was clinically associated with lower incidence of AKP, a statistically significantly reduction in VAS, compared with NPD. Therefore, we believe current evidence insufficiently supports the continued use of PD in AKP prevention in patients undergoing non-resurfaced TKA.

In the inclusion of ten RCTs, two trials on PD compared with NPD had similar effectiveness in terms of anterior knee pain after TKA [3, 11]. A study [19] revealed no substantial differences in pain at 3-month, 6-month, or 5-year follow-up in patients undergoing nonresurfaced TKA, and similar results were also observed in several other studies, comparing electrocautery with non-electrocautery [2, 3 , $11,13]$. Furthermore, two meta-analyses [23, 24] showed that PD did not decrease risks of anterior knee pain or improve clinical outcomes at 12-month follow-up. Xie et al. [23] still recommended PD because of its good safety profile. However, Zhang et al. [24] did not clearly recommend cauterization, though there was improvement. Other meta-analyses $[25,26]$ showed no improvement and did not recommend patellar cauterization in patients undergoing TKA.

Our study showed that PD led to a statistically significant improvement in post-operative ROM and PS, despite of high heterogeneity in ROM. There was no statistically significant difference but clinical increases in KSS function and KSS knee, though different scoring systems could result in variations in the objective assessment of knee function and contribute to the observed heterogeneity. A metaanalysis by Zhang et al. [24] also found PD was associated with better clinical outcome based on KSS and ROM definitely. However, the inclusion of a recent RCT in this meta-analysis by van Jonbergen et al. [9] showed different outcomes: improvements in postoperative WOMAC total and function scores of PD group were not observed at 1-year follow-up; No differences were at the 3.7year follow-up interval [12]. A recent quasi-randomized study [10] found no difference in functional outcome scores at 1-month, 6months, 1-year, or 2-year follow-up between PD and NPD after simultaneous bilateral TKA of non-resurfaced patella. A trial comparing 
patelloplasty only and patelloplasty combined with PD found no major differences in pain and functional outcomes 3 years after surgery [27].

Our study demonstrated that no significant difference in complications between PD and NPD with no heterogeneity, despite of a relatively high RR of complications in PD group. It was similar to some previous studies [12,13,19,24, 27], not similar to other studies reporting the complications related with PD including patellar fracture, dislocation, subluxation, and maltracking, or an extensor mechanism injury. Revision or re-operation cases were six out of the 503 knees in PD group and 13 out of the 502 knees in NPD group. The reasons for revision or reoperation were early aseptic loosening of femoral implants, periprosthetic fracture of the tibia, residual AKP and deep infection. No significant difference in revision or re-operation between PD and NPD was observed.

This study has several strengths. The present meta-analysis is the first to include the latest RCTs to date in this area, thus providing the most comprehensive update on the effectiveness and safety of PD for AKP prevention. We have utilized a detailed and robust search strategy that spanned multiple databases and was without language restriction. This allowed us to include trials from all over the world, improving the generalizability of our findings. Only RCTs were included, hence the inherent selection bias associated with this study design were removed by excluding observational studies.

This study has several limitations, with most inherent to the meta-analysis. Most studies had a high risk of bias in at least 1 domain. The analysis was limited by the few relevant RCTs [22] that have been published and small sample sizes given the outcomes of interest. The low adverse events (complication and reoperation or revision) rate in some trials resulted in wide $95 \%$ Cls around the RRs, thus reducing the precision of the respective estimates. Furthermore, there was variability in the populations assessed, the depth of patellar denervation, type of implant, the reporting of outcomes and adverse events, and follow-up duration. These factors potentially could have led to biased estimates, despite partly being assessed in subgroup analyses. There was statistically significant heterogeneity among the studies that could not be explained by several relevant study-level characteristics, suggesting that other factors might be responsible.

\section{Conclusions}

This meta-analysis showed that no difference in anterior knee pain between PD and NPD in patients undergoing non-resurfaced TKA. PD, compared with NPD, could improve clinical outcome in VAS, post-operative ROM and PS. We therefore do not robustly recommend patellar denervation in patients undergoing non-resurfaced TKA. However, further large multicenter RCTs with good design, large number of participants and long-term follow-ups are necessary to determine the effectiveness and safety of PD in TKAs.

\section{List Of Abbreviations}

AKP: anterior knee pain; KSS function: American Knee Society function scores; KSS knee: American Knee Society knee scores; NPD: no patellar denervation; PD: patellar denervation; PS: patellar scores; RCTs: randomized clinical trials; ROM: range of motion; TKA: total knee arthroplasty; VAS: visual analogue scale.

\section{Declarations}

\section{Acknowledgments}

Not applicable.

\section{Authors' contributions}

H.L. contributed to the conception and design of the study, the acquisition of data, interpretation of the results and writing the final manuscript. Z.L. contributed to the conception and design of the study, the acquisition of data, interpretation of the results and writing the final manuscript. Q.Z. contributed to data extraction from the database and the data statistical analysis. W.G. contributed to the conception and design of the study, provided a critical revision of the manuscript. All authors read and approved the final manuscript.

\section{Funding}

This study was funded by National Natural Science Foundation of China (grant number 81703896, 81673776), Beijing municipal science and technology commission (grant number Z171100001017209), and the Capital Health Research and Development of 
Special (grant number 2016-2-4062). The Fund's role is to provide review and publishing costs.

\section{Availability of data and materials}

Not applicable.

\section{Ethics approval and consent to participate}

This study dealt with published data only; no ethical approval was needed.

\section{Consent for publication}

Not applicable.

\section{Competing interests}

The authors declare that they have no competing interests.

\section{References}

1. van Jonbergen HP, Reuver JM, Mutsaerts EL, Poolman RW. Determinants of anterior knee pain following total knee replacement: a systematic review. Knee Surg Sports Traumatol Arthrosc. 2014;22(3):478-99.

2. Altay MA, Ertü rk C, Altay N, Akmese R, Isikan UE. Patellar denervation in total knee arthroplasty without patellar resurfacing: a prospective, randomized controlled study. Orthop Traumatol Surg Res. 2012;98:421-425.

3. Baliga S, McNair CJ, Barnett KJ, MacLeod J, Humphry RW, Finlayson D. Does circumpatellar electrocautery improve the outcome after total knee replacement? - A prospective, randomised, blinded controlled trial. Bone Joint J. 2012;94: 1228-1233.

4. Pavlou G, Meyer C, Leonidou A, As-Sultany M, West R, Tsiridis E. Patellar resurfacing in total knee arthroplasty: does design matter? - A meta-analysis of 7075 cases. J Bone Joint Surg Am. 2011;93:1301-1309.

5. Dye SF. The pathophysiology of patellofemoral pain. Clin Orthop Relat Res. 2005;436;100-110.

6. Maralcan G, Kuru I, Issi S, Esmer AF, Tekdemir I, Evcik D.The innervation of patella: Anatomical and clinical study. Surg Radiol Anat. 2005;27:331-335.

7. Fan L, Ge Z, Zhang C, Li J, Yu Z, Dang X, Wang K. Circumferential electrocautery of the patella in primary total knee replacement without patellar replacement: a meta-analysis and systematic review. Sci Rep 2015;5:9393.

8. Dajani KA, Stuart MJ, Dahm DL, Levy BA. Arthroscopic treatment of patellar clunk and synovial hyperplasia after total knee arthroplasty. J Arthroplasty. 2010;25:97-103.

9. van Jonbergen HPW, Scholtes VAB, van Kampen A, Poolman RW. A randomised, controlled trial of circumpatellar electrocautery in total knee replacement without patellar resurfacing. J Bone Joint Surg Br. 2011;93:1054-1059.

10. Budhiparama N C, Hidayat $\mathrm{H}$, Novito $\mathrm{K}$, et al. Does circumferential patellar denervation result in decreased knee pain and improved patient-reported outcomes in patients undergoing non-resurfaced, simultaneous bilateral total knee arthroplasty? Clin Orthop Relat Res. 2019;00:1-14.

11. Pulavarti RS, Raut V V., McLauchlan GJ. Patella denervation in primary total knee arthroplasty: a randomized controlled trial with 2 years of follow-up. J Arthroplasty 2014;29:977-981.

12. van Jonbergen HPW, Scholtes VAB, Poolman RW. A randomised controlled trial of circumpatellar electrocautery in total knee replacement without patellar resurfacing: A concise follow- up at a mean of 3.7 years. J Bone Joint Surg Br. 2014;96: 473-478.

13. Yim SJ, Jang MS, Kim WJ, Lee SH, Kang HK. The effect of electrocautery around the patellar rim in patellar non-resurfacing total knee arthroplasty. Knee Surg Relat Res. 2012;24:104-107.

14. Moher D, Liberati A, Tetzlaff J, Altman DG, PRISMA Group. Preferred reporting items for systematic reviews and meta-analyses: the PRISMA statement. J Clin Epidemiol. 2009;62(10): 1006-1012.

15. Higgins JP, Altman DG, Gøtzsche PC, et al; Cochrane Bias Methods Group; Cochrane Statistical Methods Group. The Cochrane Collaboration's tool for assessing risk of bias in randomised trials. BMJ. 2011;343:d5928.

16. Higgins JP, Thompson SG, Deeks JJ, Altman DG. Measuring inconsistency in meta-analyses. BMJ. 2003; 327(7414):557-560. 
17. Tufanaru C, Munn Z,Stephenson M, Aromataris E. Fixed or random effects meta-analysis? common methodological issues in systematic reviews of effectiveness. Int J Evid Based Healthc. 2015;13(3): 196-207.

18. Alomran, A. Effect of patellar denervation on mid-term results after non-resurfaced total knee arthroplasty. A randomised, controlled trial. Acta Orthop Belg. 2015;81(4):609-613.

19. Kwon, S.K., et al. Is Electrocautery of patella useful in patella non-resurfacing total knee arthroplasty? : a prospective randomized controlled study. J Arthroplasty. 2015; 30(12):2125-7.

20. Motififard M, Nazem K, Zarfeshani A, Zarfeshani K. Effect of patellar electrocautery neurectomy on postoperative pain among patients referred for total knee arthroplasty. Adv Biomed Res. 2018;7:9.

21. Reddy KJ, Dikshith SRK, Raviteja R. Patelloplasty in total knee arthroplasty with circumpatellar denervation versus without denervation: a randomized prospective trial. J Orthop Ther 2018;JORT-197.

22. Saoud AMF. Patellar denervation in non-patellar resurfacing total knee arthroplasty. Pan Arab J Orth Trauma. 2004;8:25-30.

23. Xie X, Pei F, Huang Z, Tan Z, Yang Z, Kang P. Does patellar denervation reduce post-operative anterior knee pain after total knee arthroplasty? Knee Surg Sports Traumatol Arthrosc. 2015; 23:1808-1815.

24. Zhang P, Liu H, Yan W-S, Wang W-L. Is patellar denervation necessary in total knee arthroplasty without patellar resurfacing? Knee Surg Sports Traumatol Arthrosc. 2016;24:2541-2549.

25. Cheng T, Zhu C, Guo Y, Shi S, Chen D, Zhang X. Patellar denervation with electrocautery in total knee arthroplasty without patellar resurfacing: a meta-analysis. Knee Surg Sports Traumatol Arthrosc. 2014;22:2648-2654.

26. Findlay I, Wong F, Smith C, Back D, Davies A, Ajuied A. Non- resurfacing techniques in the prevention of the patella at total knee arthroplasty: a systematic review and meta-analysis. Knee. 2016;23:191-197.

27. Gupta S, Augustine A, Horey L, Meek RMD, Hullin MG, Mohammed A. Electrocautery of the patellar rim in primary total knee replacement: beneficial or unnecessary? J Bone Joint Surg Br. 2010;92:1259-1261.

\section{Table}

Table 1.

\begin{tabular}{|c|c|c|c|c|c|c|c|c|c|c|c|c|c|}
\hline \multirow[t]{2}{*}{ Study } & \multirow[t]{2}{*}{ Year } & \multirow[t]{2}{*}{ Country } & \multicolumn{2}{|c|}{ No. knees } & \multicolumn{2}{|c|}{$\begin{array}{c}\text { Mean age } \\
\text { (years) }\end{array}$} & \multirow[t]{2}{*}{ Diagnosis } & \multirow{2}{*}{$\begin{array}{c}\text { Depth of } \\
\text { electrocautery }\end{array}$} & \multirow{2}{*}{$\begin{array}{c}\text { Type of } \\
\text { tibial } \\
\text { plateau }\end{array}$} & \multirow[t]{2}{*}{ Approach } & \multirow[t]{2}{*}{ Outcomes } & \multirow[t]{2}{*}{ Design } & \multirow{2}{*}{$\begin{array}{l}\text { Follow- } \\
\text { up } \\
\text { (months) }\end{array}$} \\
\hline & & & $\mathrm{PD}$ & NPD & $\frac{\mathrm{PD}}{\mathrm{PD}}$ & NPD & & & & & & & \\
\hline $\begin{array}{l}\text { Motififard } \\
\text { et al. }\end{array}$ & 2018 & Iran & 46 & 46 & 64.3 & 68 & NA & $1-2 \mathrm{~mm}$ & NA & MV & $4,5,6,7$ & $\begin{array}{l}\text { single- } \\
\text { centre }\end{array}$ & 10 \\
\hline $\begin{array}{l}\text { Reddy et } \\
\text { al. }\end{array}$ & 2018 & India & 50 & 49 & 63.6 & 63.6 & $\mathrm{OA} / \mathrm{RA}$ & $2-3 \mathrm{~mm}$ & FB & MP & 2 & $\begin{array}{l}\text { single- } \\
\text { centre }\end{array}$ & 24 \\
\hline $\begin{array}{c}\text { Kwon et } \\
\text { al. }\end{array}$ & 2015 & Korea & 50 & 50 & 66.3 & 67 & $\mathrm{OA}$ & $1 \mathrm{~mm}$ & FB & MP & $\begin{array}{c}4,5,6,8 \\
9\end{array}$ & $\begin{array}{l}\text { ningle- } \\
\text { centre }\end{array}$ & 60 \\
\hline $\begin{array}{l}\text { Alomran } \\
\text { et al. }\end{array}$ & 2015 & Belgium & 92 & 92 & NA & NA & OA & $1 \mathrm{~mm}$ & FB & MP & $1,3,8,9$ & $\begin{array}{l}\text { single- } \\
\text { centre } \\
\text { RCT }\end{array}$ & $\begin{array}{l}37.4 \\
\text { (PD) } \\
39.0\end{array}$ \\
\hline $\begin{array}{l}\text { Van } \\
\text { Jonbergen }\end{array}$ & 2014 & $\begin{array}{l}\text { The } \\
\text { Netherlands }\end{array}$ & 103 & 99 & 70 & 71 & OA & Over $1 \mathrm{~mm}$ & FB & MP & $1,8,9$ & $\begin{array}{l}\text { single- } \\
\text { centre }\end{array}$ & $\begin{array}{l}\text { (NPD) } \\
44.4\end{array}$ \\
\hline $\begin{array}{l}\text { et al. } \\
\text { Pulavarti } \\
\text { et al. }\end{array}$ & 2014 & UK & 63 & 63 & 69.9 & 69.8 & OA & NA & NA & MP & $\begin{array}{c}1,2,3,4 \\
5,6,7,8, \\
9\end{array}$ & $\begin{array}{l}\text { RCT } \\
\text { single- } \\
\text { centre } \\
\text { RCT }\end{array}$ & $\begin{array}{l}26.5 \\
\text { (PD) } \\
26.3\end{array}$ \\
\hline Yim et al. & 2012 & Korea & 50 & 50 & 70.2 & 70.2 & OA & Within $2-3 \mathrm{~mm}$ & NA & MP & $1,8,9$ & $\begin{array}{l}\text { single- } \\
\text { centre }\end{array}$ & $\begin{array}{c}(\mathrm{NPD}) \\
21\end{array}$ \\
\hline $\begin{array}{c}\text { Baliga et } \\
\text { al. }\end{array}$ & 2012 & UK & 91 & 94 & 69 & 69.2 & $\mathrm{OA}$ & Within $1 \mathrm{~mm}$ & $\mathrm{MB} \& \mathrm{FB}$ & MP & 8,9 & $\begin{array}{l}\text { single- } \\
\text { centre }\end{array}$ & 12 \\
\hline $\begin{array}{l}\text { Altay et } \\
\text { al. }\end{array}$ & 2012 & Turkey & 35 & 35 & 68 & 68 & NA & $2-3 \mathrm{~mm}$ & NA & MV & $\begin{array}{c}2,3,4,6 \\
\quad 7,8,9\end{array}$ & $\begin{array}{l}\text { single- } \\
\text { centre }\end{array}$ & 36 \\
\hline $\begin{array}{c}\text { Saoud et } \\
\text { al. }\end{array}$ & 2004 & Egypt & 19 & 19 & NA & NA & OA & $1 \mathrm{~mm}$ & FB & MP & $1,8,9$ & $\begin{array}{l}\text { single- } \\
\text { centre } \\
\text { RCT }\end{array}$ & $\begin{array}{c}11(\mathrm{PD}) \\
10 \\
\text { (NPD) }\end{array}$ \\
\hline
\end{tabular}

PD patellar denervation with electrocautery, NPD no patellar denervation with electrocautery, OA osteoarthritis, RA rheumatoid arthritis, FB fixed-bearing prosthesis, MB mobile-bearing prosthesis, MP medial parapatellar approach, MV midvastus approach, NA data not available. 1, AKP; 2, VAS; 3, ROM; 4, PS; 5, 3-month post-operative PS; 6, KSS knee; 7, KSS function; 8, Total incidence of complications; 9, Total incidence of revisions or re-operation. 


\section{Figures}

\section{Prisma Flow diagram}

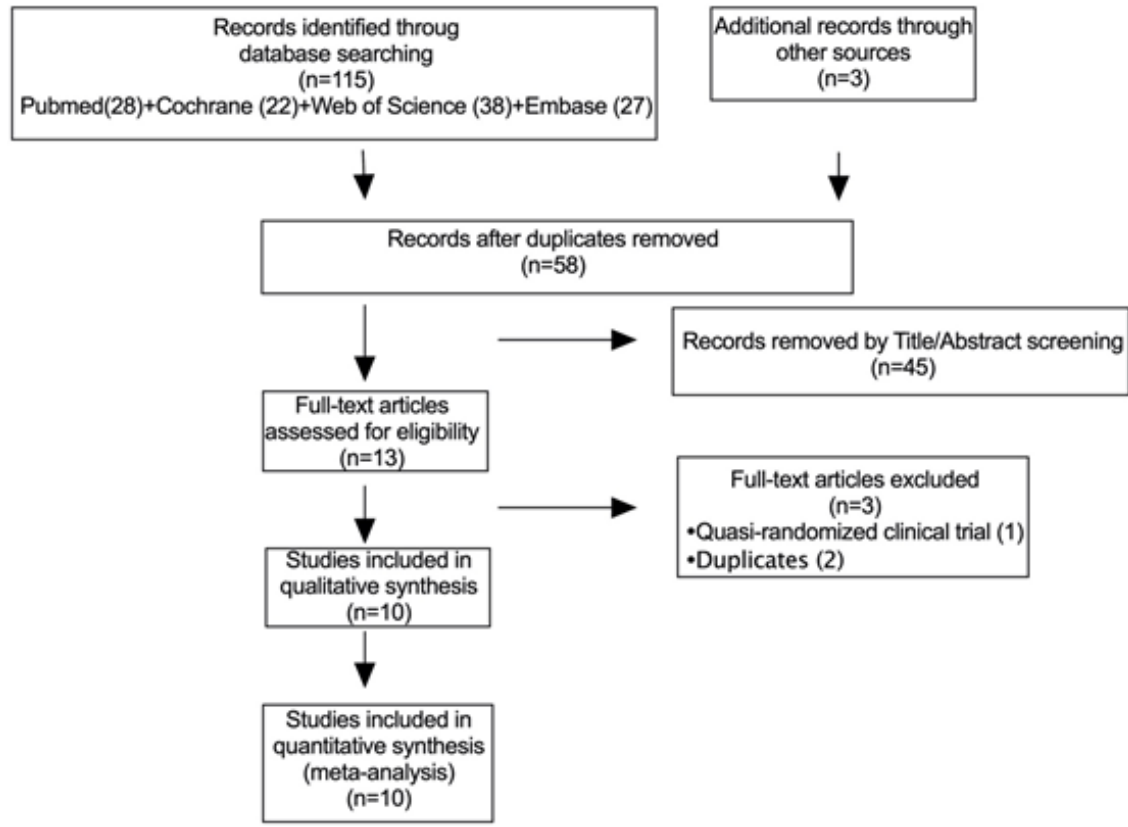

Figure 1

PRISMA flowchart for the study data.

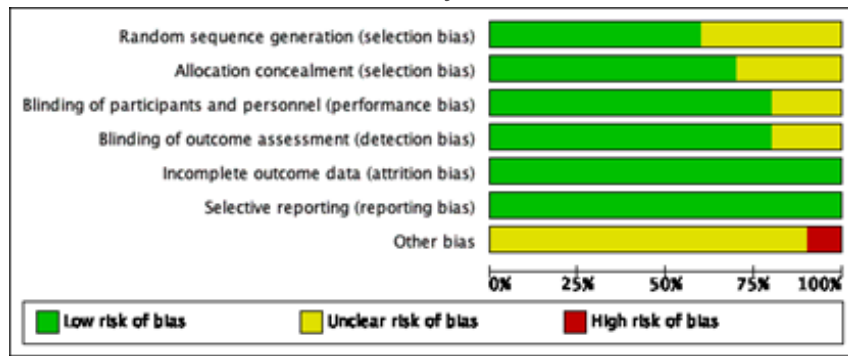

\section{Figure 2}

Risk of bias graph of included randomized controlled trials. 


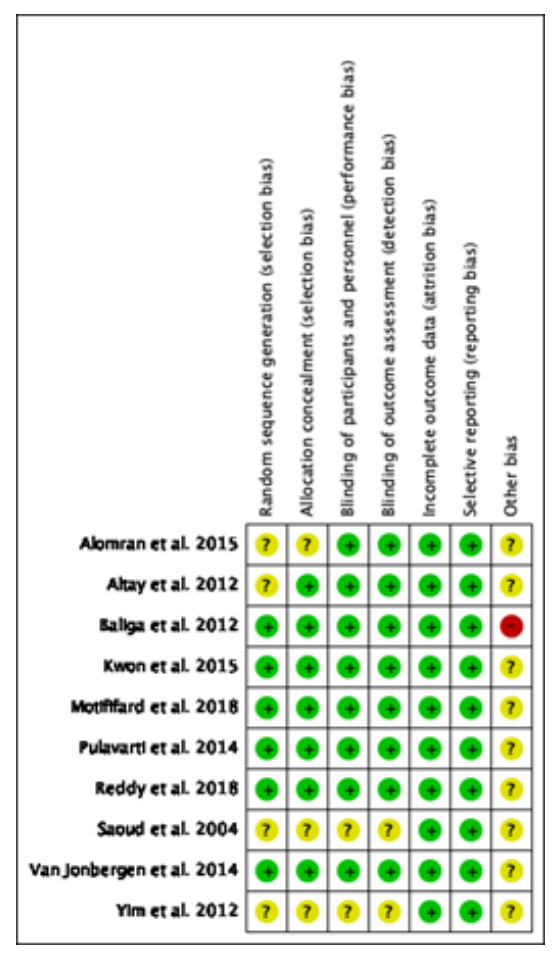

\section{Figure 3}

Risk-of-bias summary of included randomized controlled trials. +, no bias; -, bias; ?, bias unknown

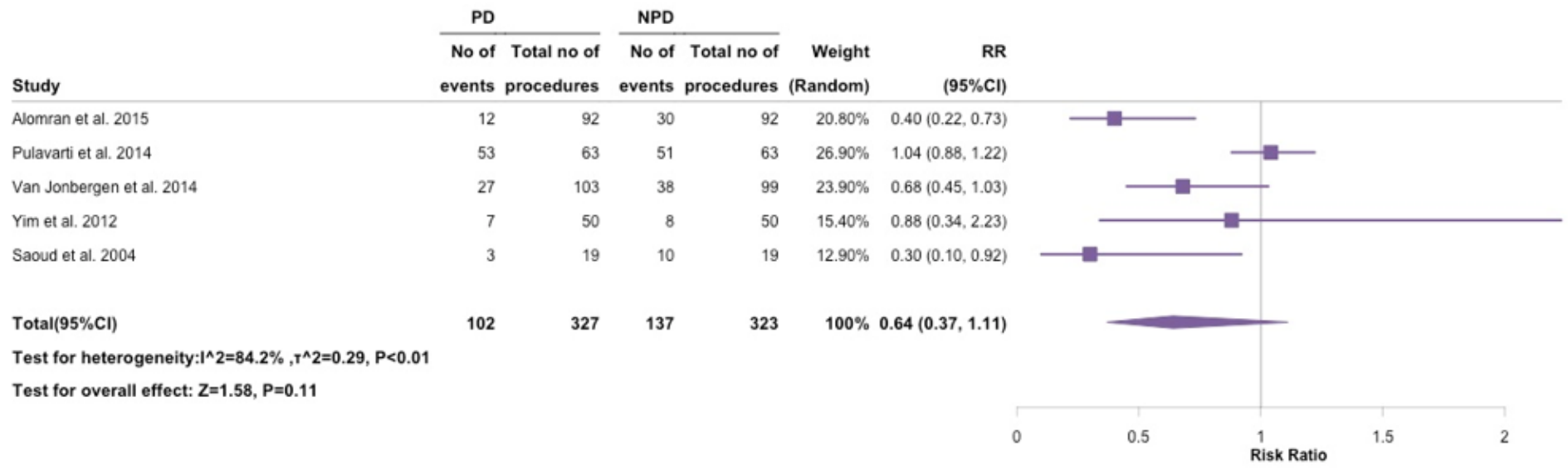

\section{Figure 4}

incidence of AKP 


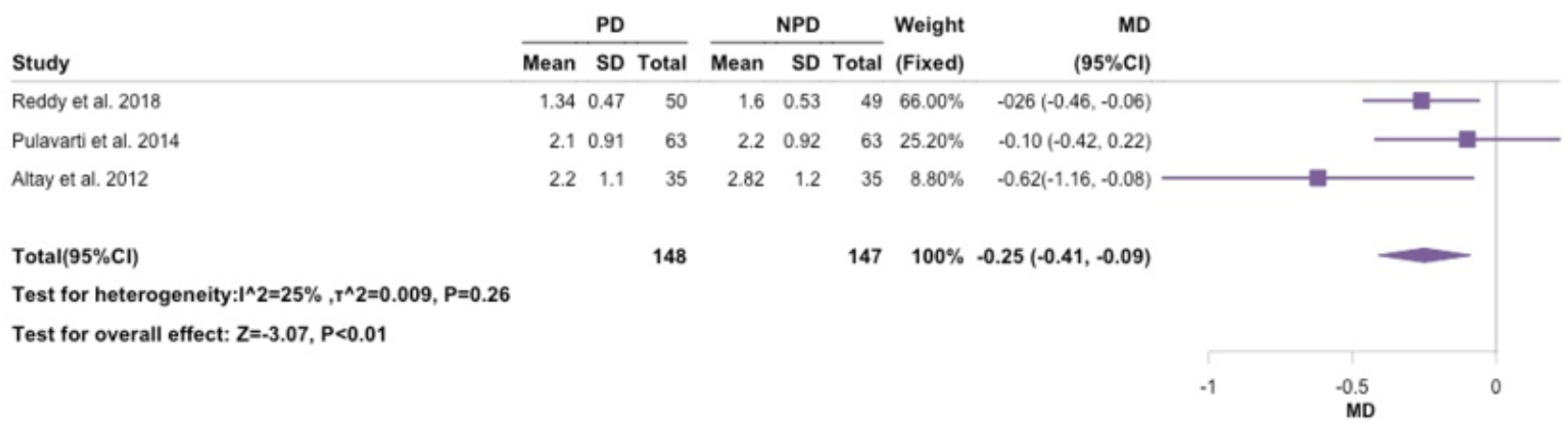

\section{Figure 5}

VAS (visual analogue scale)

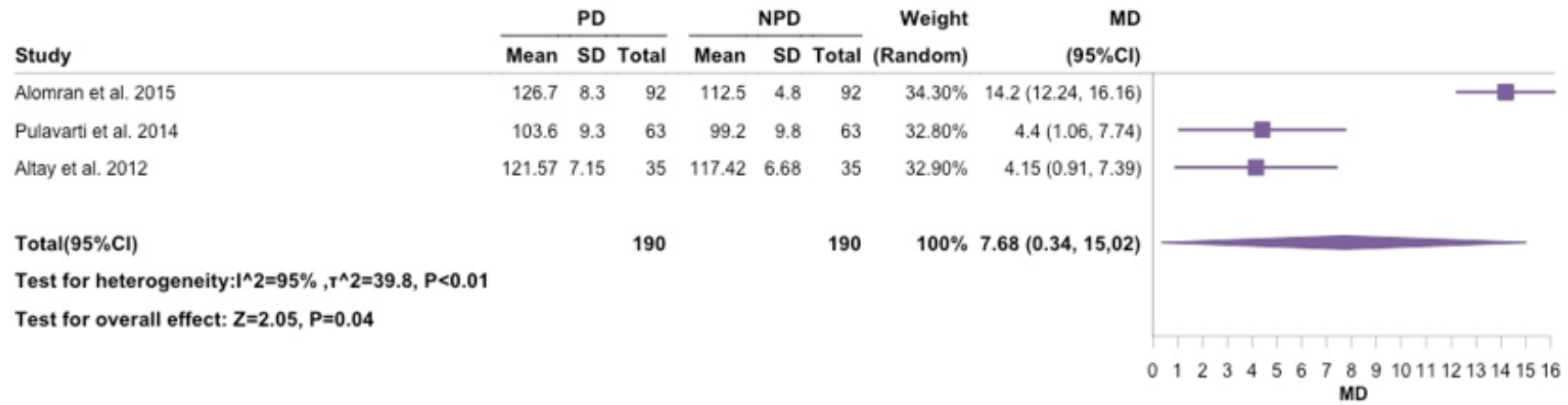

\section{Figure 6}

ROM (range of motion)

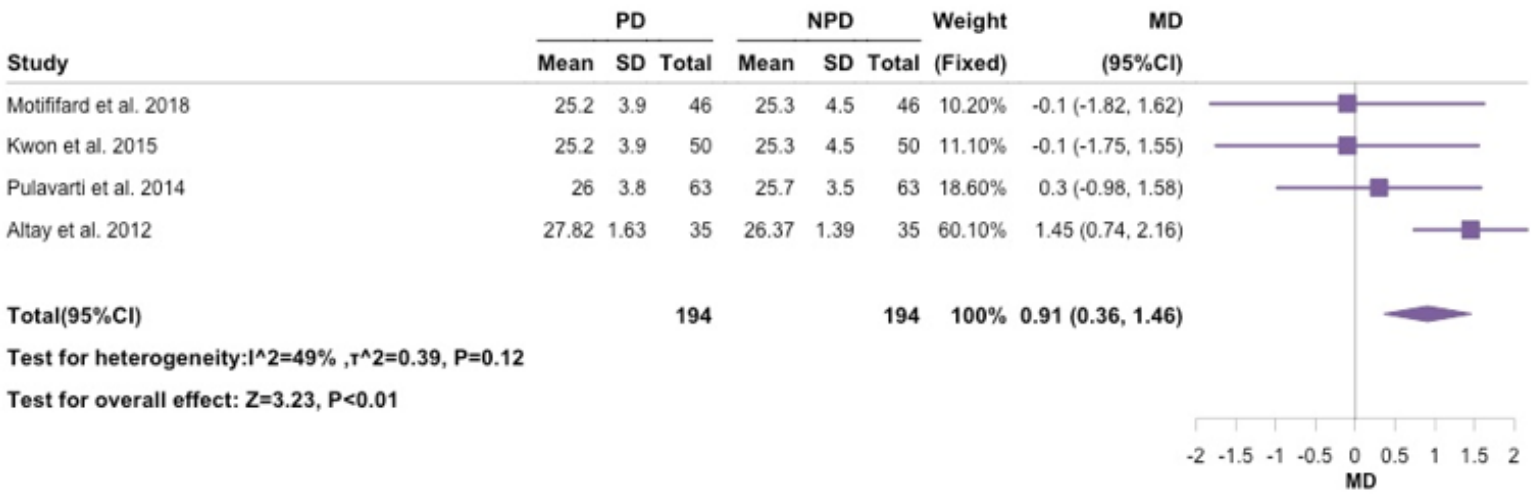

Figure 7

PS (patellar scores) 


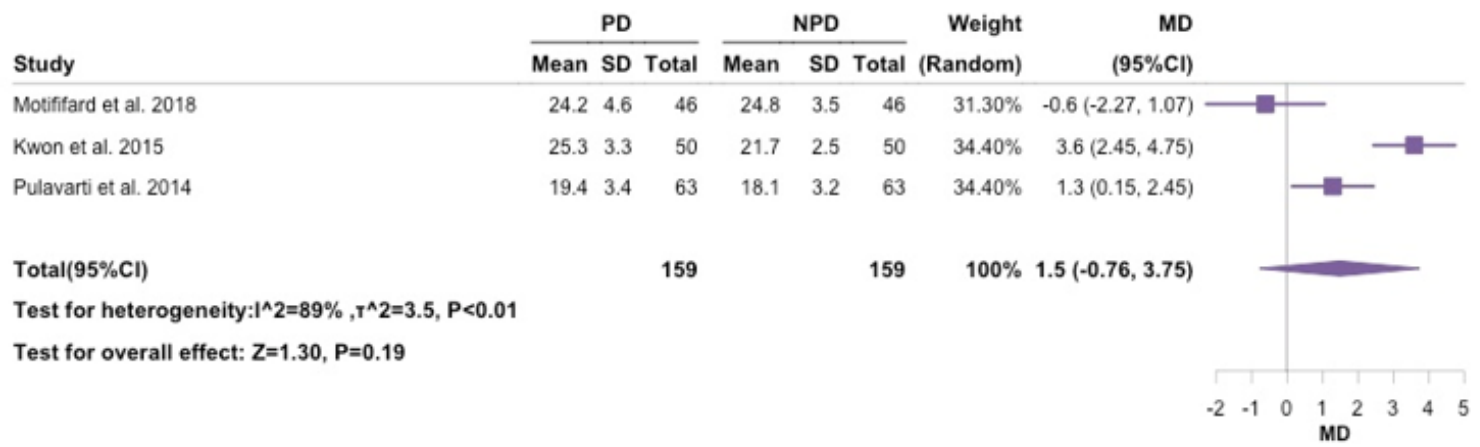

\section{Figure 8}

3-month post-operative PS (patellar scores)

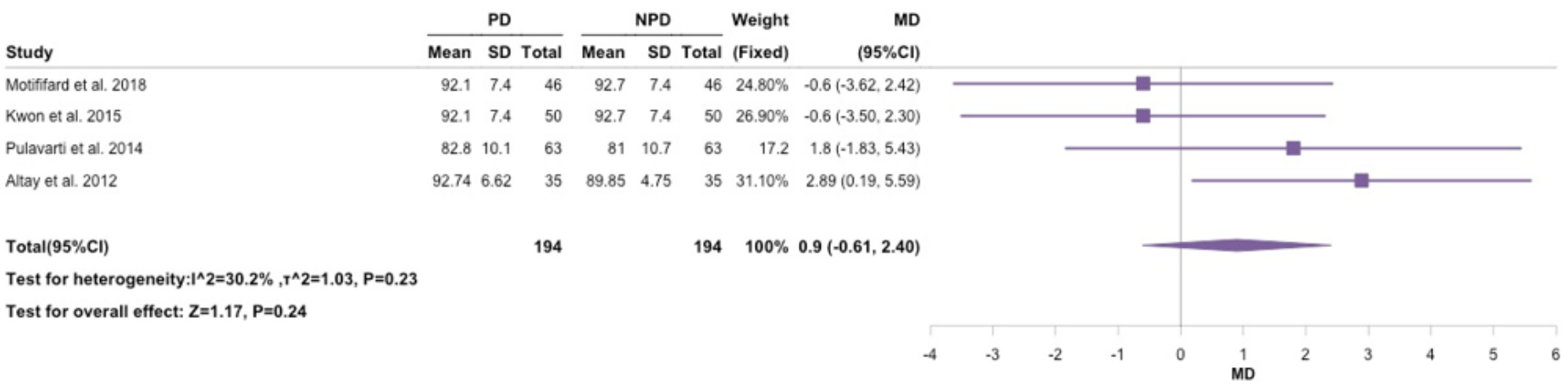

\section{Figure 9}

KSS knee (American Knee Society knee scores)

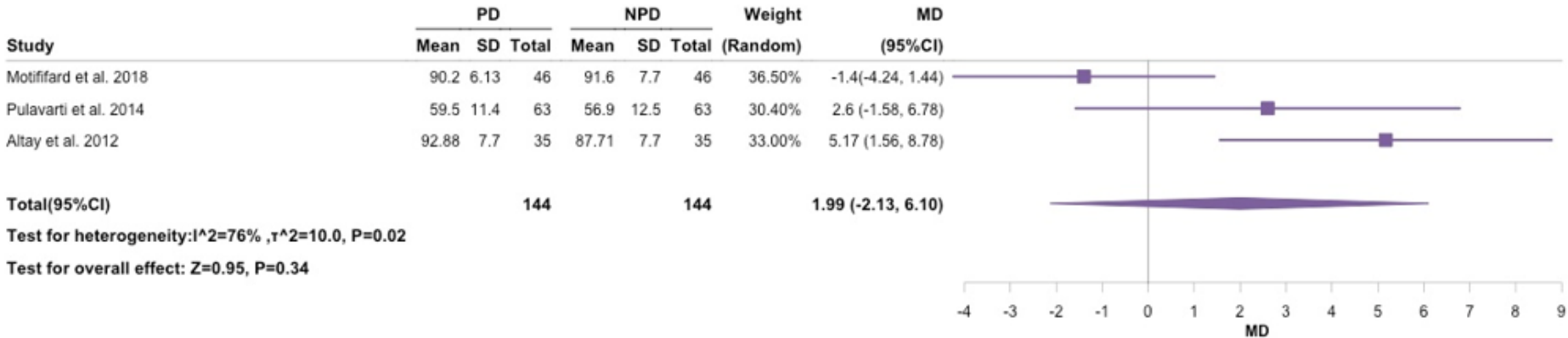

\section{Figure 10}

KSS function (American Knee Society function scores) 


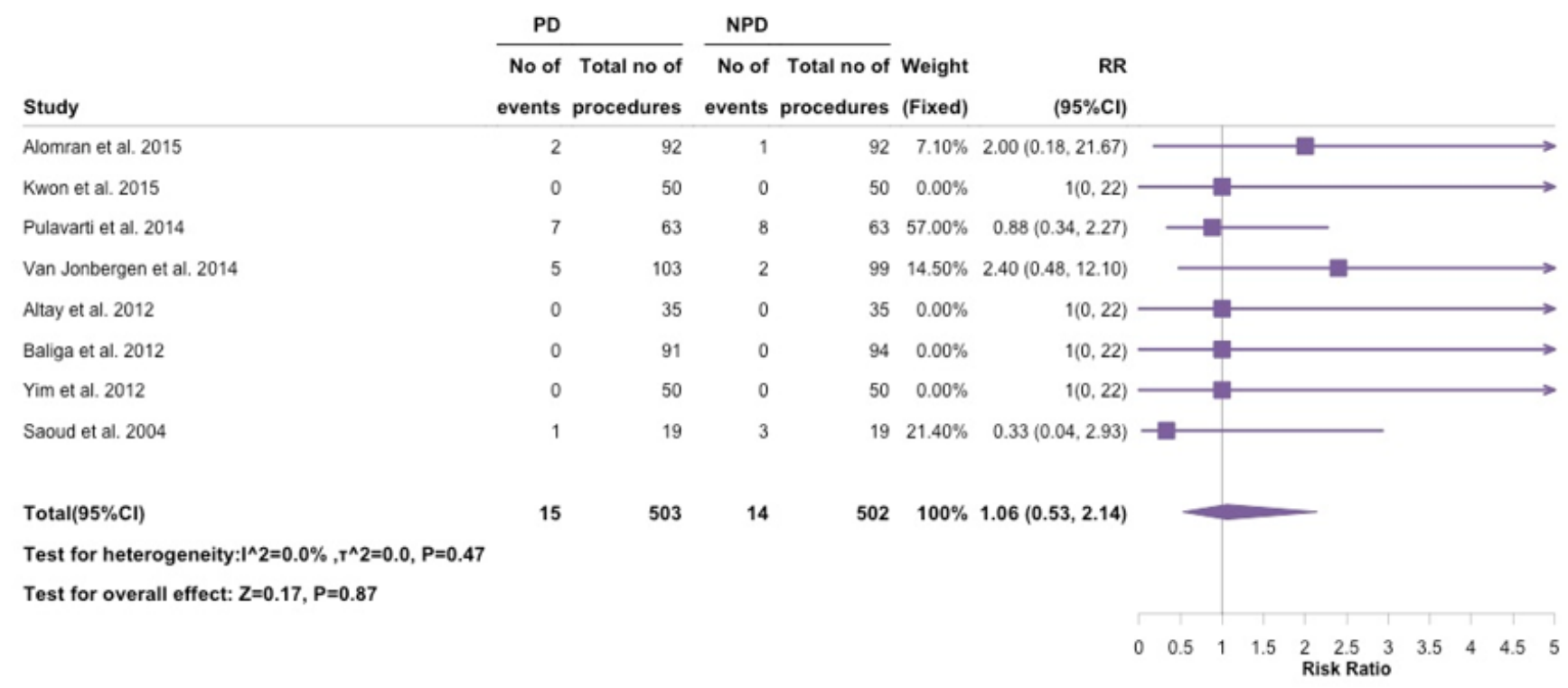

\section{Figure 11}

Total incidence of complications

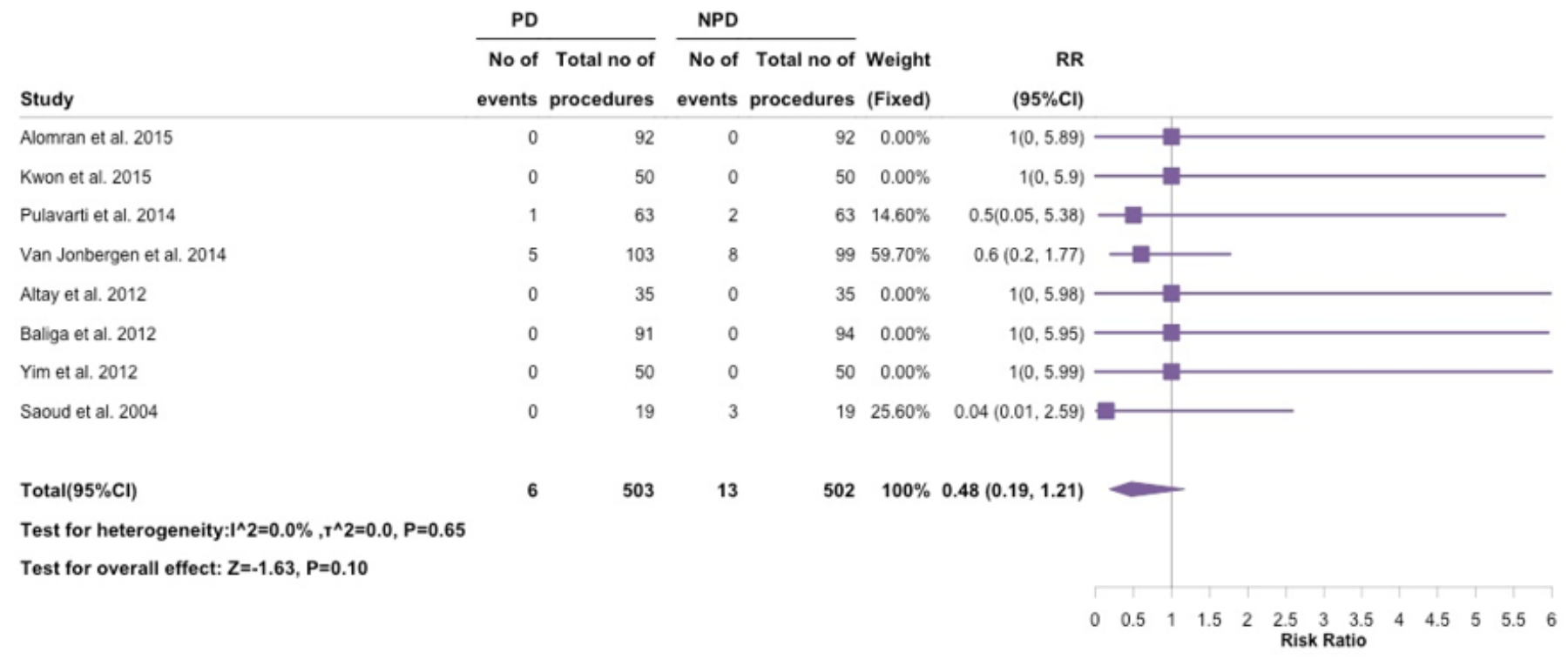

\section{Figure 12}

Total incidence of revisions or re-operation 


\begin{tabular}{|c|c|c|c|c|c|c|c|c|c|c|}
\hline \multirow[b]{2}{*}{ Subgroup } & \multirow[b]{2}{*}{$\begin{array}{l}\text { No. of } \\
\text { Studies }\end{array}$} & \multicolumn{2}{|l|}{ PD } & \multicolumn{2}{|l|}{ NPD } & \multirow[b]{2}{*}{ Weight } & \multirow{2}{*}{\multicolumn{3}{|c|}{$\begin{array}{r}\text { RR } \\
(95 \% \mathrm{Cl})\end{array}$}} & \\
\hline & & $\begin{array}{l}\text { No. of } \\
\text { Events }\end{array}$ & $\begin{array}{r}\text { No. of } \\
\text { Participants }\end{array}$ & $\begin{array}{l}\text { No. of } \\
\text { Events }\end{array}$ & $\begin{array}{r}\text { No. of } \\
\text { Participants }\end{array}$ & & & & & \\
\hline \multicolumn{10}{|c|}{ Location/Year of publication } & \\
\hline Europe/After 2012 & 3 & 92 & 258 & 119 & 254 & $86.93 \%$ & $<0.01$ & $89.00 \%$ & $0.76(0.64,0.92)$ & \\
\hline Others/Before 2012 & 2 & 10 & 69 & 18 & 69 & $13.07 \%$ & 0.15 & $52.00 \%$ & $0.56(0.28,1.11)$ & \\
\hline \multicolumn{10}{|l|}{ Follow-up } & \\
\hline Over 2 years & 2 & 39 & 195 & 68 & 191 & $49.91 \%$ & 0.15 & $52.00 \%$ & $0.56(0.40,0.79)$ & 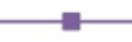 \\
\hline Within 2 years & 3 & 63 & 132 & 69 & 132 & $50.09 \%$ & 0.04 & $68.00 \%$ & $0.91(0.76,1.10)$ & \\
\hline \multicolumn{10}{|c|}{ Depth of electrocautery } & \\
\hline Within $1 \mathrm{~mm}$ & 2 & 15 & 111 & 40 & 111 & $46.11 \%$ & 0.66 & $0.00 \%$ & $0.38(0.22,0.64)$ & \\
\hline \multirow[t]{2}{*}{ Over $1 \mathrm{~mm}$} & 2 & 34 & 153 & 46 & 149 & $53.89 \%$ & 0.63 & $0.00 \%$ & $0.72(0.49,1.04)$ & \\
\hline & & & & & & & & & 0 & $\begin{array}{l}0.5 \\
\text { Risk Ratio }\end{array}$ \\
\hline
\end{tabular}

\section{Figure 13}

Effectiveness of PD Compared with NPD on incidence of AKP, grouped according to study-level characteristics

\section{Supplementary Files}

This is a list of supplementary files associated with this preprint. Click to download.

- Supplement.docx 